\title{
Gunter's Chain USA
}

National Cancer Institute

\section{Source}

National Cancer Institute. Gunter's Chain USA. NCI Thesaurus. Code C71231.

A traditional unit of length equal to $1 / 80$ mile, 22 yards, 66 feet or 20.1168 meters. 